\title{
Influence of composition and powder/water ratio on adhesion strength and initial viscosity of powder-type denture adhesives based on CMC-Na and PVM-MA
}

\author{
Hitomi OKAZAKI, Kazuhiro YOSHIDA, Takafumi EGOSHI, Kazuma TAKASE and Hiroshi MURATA \\ Department of Prosthetic Dentistry, Graduate School of Biomedical Sciences, Nagasaki University, 1-7-1 Sakamoto, Nagasaki 852-8588, Japan \\ Corresponding author, Hiroshi MURATA; E-mail: hmurata@nagasaki-u.ac.jp
}

\begin{abstract}
We evaluated the influence of the composition and powder/water (P/W) ratio of powder-type denture adhesives (DA) based on sodium carboxymethyl cellulose (CMC-Na) and poly(methyl vinyl ether-maleic anhydride) (PVM-MA) on the strength of adhesion to acrylic resin and initial viscosity. Twenty types of DA were prepared by mixing CMC-Na and PVM-MA at various weight ratios with distilled water in $\mathrm{P} / \mathrm{W}$ ratios ranging from 0.125 to 0.500 . Adhesion strength and viscosity were measured using a universal testing machine and a controlled-stress rheometer, respectively. A higher percentage of CMC-Na and higher P/W ratios resulted in higher adhesion strength and viscosity. The effect of the CMC-Na/PVM-MA weight ratio on adhesion strength and viscosity was larger than that of the P/W ratio. DA with higher viscosity had higher adhesion strength. These results suggest that the adhesion strength and initial viscosity of powder-type DA can be controlled via the P/W ratio and the CMC-Na/PVM-MA weight ratio.
\end{abstract}

Keywords: Denture adhesive, Adhesion strength, Viscosity, CMC-Na, PVM-MA

\section{INTRODUCTION}

Most developed countries have an aging population. The number of denture wearers is expected to increase, and thus problems related to dentures, such as anatomical restrictions, dry mouth, and psychological anxiety, will become more common. Dry mouth can be simply treated with a mouth moisturizer. In contrast, the inferior denture retention and stability caused by anatomical restrictions and psychological factors are difficult to control with conventional methods ${ }^{1}$. Although the use of implants is prevalent in such cases, not all patients get implants because of their oral and systemic conditions or economic situation. Denture adhesives (DA) are useful adjuncts for denture prosthesis services ${ }^{2}$. DA, which improve denture retention and stability, are available at pharmacies or drugstores ${ }^{3)}$. DA can be divided into glue and liner types ${ }^{4}$. A glue type DA, which can be in powder, cream, sheet, or tape form, uses a water-soluble polymer as the adhesive constituent and is applied to improve the retention and stability of dentures via adhesion strength ${ }^{4}$. A liner type DA is a non-aqueous paste that is applied to improve the retention and stability of dentures via adsorption ${ }^{4}$.

According to a consensus statement from American prosthetic specialists regarding glue type $\mathrm{DA}^{2}$, there have been significant advances in these types of DA over the past 20 years ${ }^{5-9}$. Although the clinical significance of DA is unclear, various studies on the clinical efficacy of glue type DA have been published ${ }^{10)}$. It has been shown that the application of DA to either well- or ill-fitting dentures leads to improvement in denture retention and wearer satisfaction ${ }^{11-13)}$. Furthermore, a shortening of masticating cycle time and increases in occlusal force and masticating rate have been observed with DA application $^{14-16)}$. It has also been found that DA influence the retentive force of dentures worn by patients with xerostomia $^{17,18)}$. Moreover, DA use in combination with diet therapy can lead to improvements in eating behavior by complete denture wearers ${ }^{19)}$. Use of both powder- and cream-type DA is recommended because the thin layer of DA does not change the occlusal vertical dimension of the dentures ${ }^{20,211}$.

Liner type DA (cushion form), namely home reliners, are used to fill the gap between the denture intaglio surface of ill-fitting dentures and the denture-bearing mucosa, resulting in enhanced adhesion. However, although liner type DA may temporarily improve the stability and retention of ill-fitting dentures, they have adverse effects, such as unusual bone loss of the residual ridge due to an inequitable distribution of masticatory force on the denture-bearing mucosa and malocclusion caused by DA deterioration. We previously reported that the use of liner type DA results in dramatic changes in viscoelastic properties over time and considerably high water absorption ${ }^{22}$. Therefore, liner type DA are not recommended for denture wearers ${ }^{20,23)}$.

Glue type DA contain a water-soluble polymer, such as sodium carboxymethyl cellulose (CMC-Na), poly(methyl vinyl ether-maleic anhydride) (PVM-MA), or sodium polyacrylate, as the main component ${ }^{24,25)}$. These polymers absorb saliva, resulting in a highly viscous layer between the denture intaglio surface and the denture-bearing mucosa, improving adhesion strength to the dentures. Powder-type DA mainly consist of water-soluble polymers and include no ointment bases. Although it is easier to remove such DA from the oral mucosa compared to cream-type DA after usage, it is difficult to obtain a consistent viscosity because of the variable quantity of water added by the patient. Cream-type DA contain petrolatum and liquid paraffin, which are ointment bases, in addition to the above components. Although several reports on the properties of commercially available DA have been published ${ }^{26-29)}$, 
scant information is available regarding the relationship between their mechanical properties and composition.

CMC-Na and PVM-MA are the main components of glue type DA. They are the most frequently used watersoluble polymers. Therefore, in the present study, we evaluated powder-type DA, which do not contain an ointment (e.g., petrolatum and liquid paraffin), based on CMC-Na and PVM-MA mixed with water at various powder/water $(\mathrm{P} / \mathrm{W})$ ratios.

Denture retention is defined as the resistance in the movement of a denture away from its tissue foundation in a vertical direction, and denture stability is defined as that in a lateral direction. A previous study demonstrated that a higher viscosity of saliva led to higher strength of adhesion to acrylic resin, and thus higher denture retention and stability ${ }^{30)}$. Therefore, adhesion strength to acrylic resin is an indicator of denture retention and stability. Adhesion strength is one of the most important requirements for DA as it directly affects patient satisfaction. The initial viscosity of DA can affect manipulation by users and the degree of spread on the denture-bearing mucosa during application.

The aim of the present study was to evaluate powder-type DA in terms of the effects of the composition of CMC-Na and PVM-MA and the P/W ratio on the strength of adhesion to acrylic resin and initial viscosity. We hypothesized that the composition of CMC-Na and PVM-MA and the $\mathrm{P} / \mathrm{W}$ ratio influence adhesion strength and initial viscosity. In addition, we investigated whether DA with a higher percentage of CMC-Na and a higher $\mathrm{P} / \mathrm{W}$ ratio have higher adhesion strength and initial viscosity.

\section{MATERIALS AND METHODS}

CMC-Na (Lot No: SAE0740; $\mathrm{M}_{\mathrm{w}}=119.0 \times 10^{4}$; $\mathrm{M}_{\mathrm{n}}=11.3 \times 10^{4}$; polydispersity $=10.5$; particle size: 75 $\mu \mathrm{m}$ or less; degree of etherification: 0.7-0.8; Wako Pure Chemical Industries, Osaka, Japan) and PVMMA (Lot No: MKBP4375V; $\mathrm{M}_{\mathrm{w}}=21.6 \times 10^{4} ; \mathrm{M}_{\mathrm{n}}=8.0 \times 10^{4}$; polydispersity=2.7; particle size: $8.2 \mu \mathrm{m}$; Sigma-Aldrich, St. Louis, MO, USA) were used in this study. Both are water-soluble polymers and generally included in powder-type DA. Five types of DA were made by mixing these polymers: $100 \% \mathrm{CMC}-\mathrm{Na} / 0 \% \mathrm{PVM}-\mathrm{MA}$, 75\%CMC-Na/25\%PVM-MA， 50\%CMC-Na/50\%PVMMA, 25\%CMC-Na/75\%PVM-MA, and 0\%CMCNa/100\%PVM-MA (by weight). Ten grams of each DA were mixed with distilled water at $4 \mathrm{P} / \mathrm{W}$ ratios, namely $0.125,0.250,0.375$, and 0.500 , for $30 \mathrm{~s}$ using an automatic mixer (Super Rakuneru Fine, GC, Tokyo, Japan).

\section{Adhesion strength}

The measurement of adhesion strength was performed using a previously described method ${ }^{28)}$. Each tested DA was placed between acrylic resin plates and its adhesion strength was measured using a compact table-top universal tester (EZ Test/CE, Shimadzu, Kyoto, Japan, Fig. 1). A pressure-sensitive shaft with a circular base and a diameter of $20.0 \pm 0.5 \mathrm{~mm}$ was prepared using acrylic resin (Acron, GC), according to ISO specification $10873^{4}$, then fixed into position in the load detector of the universal testing machine. The sample holder, also made of acrylic resin, had a hole with a diameter of $22 \pm 1 \mathrm{~mm}$ and a depth of $0.5 \pm 0.1 \mathrm{~mm}$. The surfaces of the pressure-sensitive shaft and the sample holder were abraded with 1000-grit silicon-carbide paper.

Two DA layer thicknesses were used, namely 0.1 and $0.5 \mathrm{~mm}$. After mixing, the tested DA was immediately placed on the sample holder using a syringe and its surface was flattened. Then, a layer thickness of 0.1 or $0.5 \mathrm{~mm}$ was applied. Following the completion of

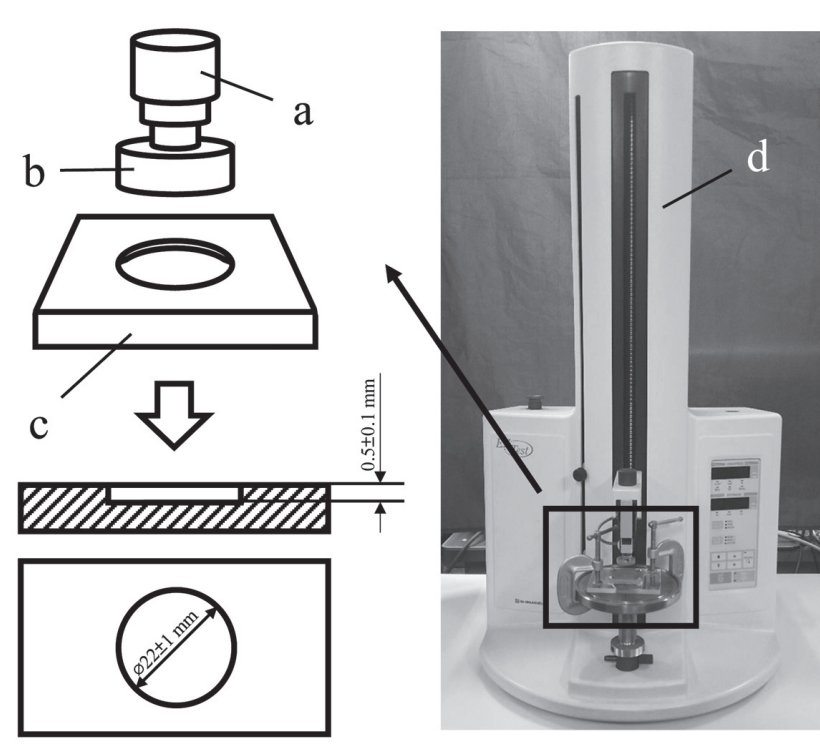

Fig. 1 Apparatus used for measuring adhesion strength of DA.

(a) Load detector, (b) pressure-sensitive shaft, (c) sample holder, and (d) compact table-top universal tester.

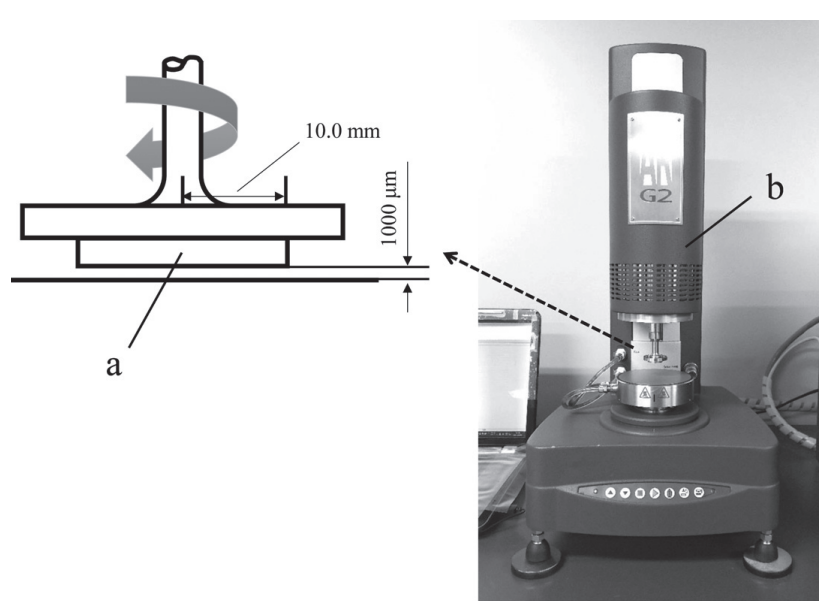

Fig. 2 Apparatus used for measuring initial viscosity of DA.
(a) Parallel
plate and
(b) controlled-stress rheometer. 
stress relaxation for $30 \mathrm{~s}$, a tensile test was performed at a cross-head speed of $5 \mathrm{~mm} / \mathrm{min}$ and the maximum adhesion strength value was recorded. Measurements were performed 5 times for each DA at $23 \pm 1^{\circ} \mathrm{C}$.

\section{Initial viscosity}

The initial viscosity of each tested DA was measured using a controlled-stress rheometer (AR-G2, TA Instruments-Waters LLC, New Castle, DE, USA, Fig. 2). A parallel plate with a diameter of $20 \mathrm{~mm}$ was used. The gap between the plates was $1,000 \mu \mathrm{m}$. A solvent trap was utilized to prevent evaporation of water from the DA. Measurements were performed at a shear rate of 0.1 to $100 \mathrm{~s}^{-1}$ at $23 \pm 1^{\circ} \mathrm{C}$. A viscosity at $1.0 \mathrm{~s}^{-1}$ was used for comparison.

\section{Statistical analysis}

Comparisons of adhesion strength were performed using 3-way analysis of variance (ANOVA). The contribution ratios ( $\rho$ ) of DA layer thickness, weight ratio of CMC-Na to PVM-MA, and P/W ratio, as well as their interactions, were determined. Comparisons of initial viscosity were performed using 2-way ANOVA. The contribution ratios ( $\rho)$ of the weight ratio of CMC-Na to PVM-MA, and P/W ratio, as well as their interactions, were determined. Regression analysis was used to determine the correlation between 2 values (adhesion strength and initial viscosity) and 2 factors (weight ratio of CMC-Na to PVM-MA and $\mathrm{P} / \mathrm{W}$ ratio). The level of statistical significance for all tests was set at $p<0.05$. SPSS Statistics 17.0 was used for all statistical analyses.

\section{RESULTS}

\section{Adhesion strength}

The results of 3-way ANOVA indicated that all examined factors had a significant influence on adhesion to acrylic resin for the powder-type DA based on CMC-Na and PVM-MA $(p<0.0005$, Table 1$)$. The contribution of the weight ratio of CMC-Na to PVM-MA was highest $(\rho=59.1 \%)$, followed by those of the P/W ratio $(\rho=19.8 \%)$ and DA layer thickness $(\rho=8.3 \%)$. The influences of the weight ratio of CMC-Na to PVM-MA and P/W ratio on adhesion strength are shown in Figs. 3 and 4, respectively, for DA layer thicknesses of 0.1 and $0.5 \mathrm{~mm}$. The adhesion strength for nearly all of the examined DA increased with increasing percentage of CMC-Na and $\mathrm{P} / \mathrm{W}$ ratio. The adhesion strength for a DA thickness of $0.5 \mathrm{~mm}$ was lower compared to that for $0.1 \mathrm{~mm}$. The DA consisting of only CMC-Na showed the highest adhesion strength, greater than $60 \mathrm{kPa}$ for a $0.1-\mathrm{mm}$ gap, whereas that consisting of only PVM-MA had the lowest adhesion strength, $1 \mathrm{kPa}$ or lower. We were able to apply polynomial approximation to all relationships between adhesion strength and both percentages of CMC-Na and $\mathrm{P} / \mathrm{W}$ ratio with high correlation coefficients $(\mathrm{r}=0.9530$ $0.9982, p<0.0005)$ in the regression analysis, except for the DA containing only PVM-MA. The correlation coefficient of the DA containing only PVM-MA for the $0.1-\mathrm{mm}$ gap was quite small $(\mathrm{r}=0.5776, p=0.032)$ and that for $0.5 \mathrm{~mm}$ did not show a significant relationship.

\section{Initial viscosity}

The results of 2-way ANOVA indicated that all examined factors had a significant influence on initial

Table 1 Three-way ANOVA for adhesion strength of powder-type denture adhesives based on CMC-Na and PVM-MA

\begin{tabular}{|c|c|c|c|c|c|c|}
\hline Source & $\mathrm{df}$ & $\begin{array}{l}\text { Sum of } \\
\text { squares }\end{array}$ & Mean square & $\mathrm{F}$ & $\begin{array}{l}\text { Significance } \\
\text { of } \mathrm{F}\end{array}$ & $\begin{array}{l}\text { Contribution } \\
\text { ratio } \rho(\%)\end{array}$ \\
\hline Material layer thickness & 1 & $1.764 \times 10^{10}$ & $1.764 \times 10^{10}$ & $4,230.215$ & 0.000 & 8.3 \\
\hline Ratio of CMC-Na and PVM-MA & 4 & $1.255 \times 10^{11}$ & $3.137 \times 10^{10}$ & $7,521.503$ & 0.000 & 59.1 \\
\hline $\mathrm{P} / \mathrm{W}$ ratio & 3 & $4.206 \times 10^{10}$ & $1.402 \times 10^{10}$ & $3,361.662$ & 0.000 & 19.8 \\
\hline $\begin{array}{l}\text { Material layer thickness } \times \text { Ratio } \\
\text { of CMC-Na and PVM-MA }\end{array}$ & 4 & $5.290 \times 10^{9}$ & $1.323 \times 10^{9}$ & 317.16 & 0.000 & 2.5 \\
\hline $\begin{array}{l}\text { Material layer thickness } \times \\
\text { P/W ratio }\end{array}$ & 3 & $1.295 \times 10^{9}$ & $4.318 \times 10^{8}$ & 103.553 & 0.000 & 0.6 \\
\hline $\begin{array}{l}\text { Ratio of CMC-Na and } \\
\text { PVM-MA×P/W ratio }\end{array}$ & 12 & $1.680 \times 10^{10}$ & $1.400 \times 10^{9}$ & 335.654 & 0.000 & 7.9 \\
\hline $\begin{array}{l}\text { Material layer thickness } \times \\
\text { Ratio of CMC-Na and } \\
\text { PVM-MA } \times \text { P/W ratio }\end{array}$ & 12 & $2.982 \times 10^{9}$ & $2.485 \times 10^{8}$ & 59.582 & 0.000 & 1.4 \\
\hline Error & 160 & $6.672 \times 10^{8}$ & $4,170,109.436$ & - & - & 0.4 \\
\hline Total & 200 & $5.207 \times 10^{11}$ & - & - & - & - \\
\hline Corrected total & 199 & $2.122 \times 10^{11}$ & - & - & - & - \\
\hline
\end{tabular}



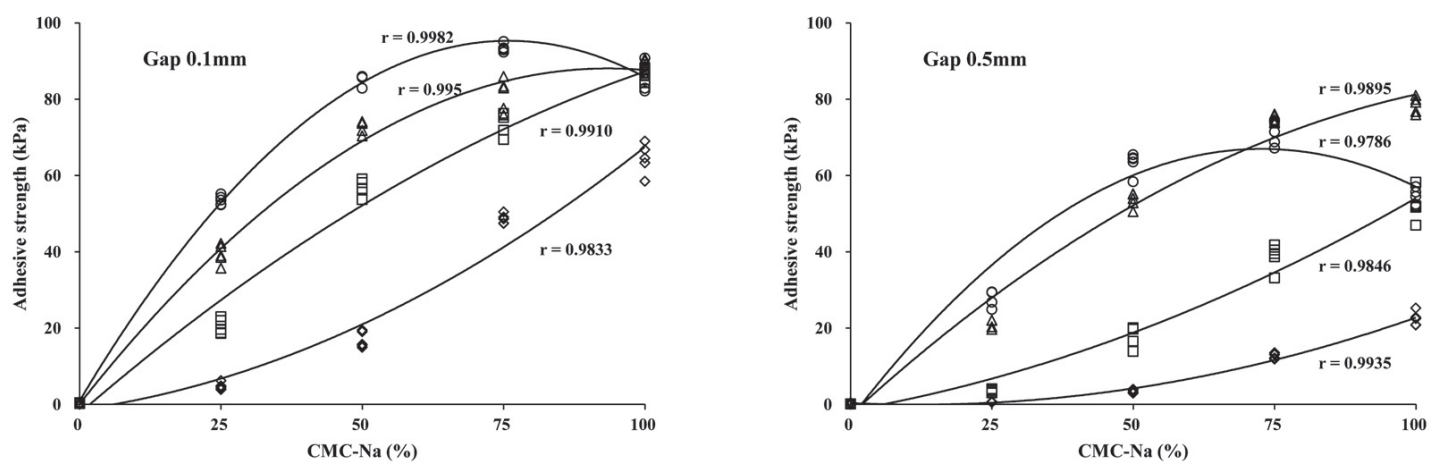

O P/W 0.500

$\triangle \mathrm{P} / \mathrm{W} 0.375$

$\square$ P/W 0.250

$\diamond \mathbf{P} / \mathrm{W} 0.125$

Fig. 3 Relationship between adhesion strength of powder-type DA based on CMC-Na and PVM-MA and weight ratio of CMC-Na to PVM-MA for gaps of 0.1 and $0.5 \mathrm{~mm}$.
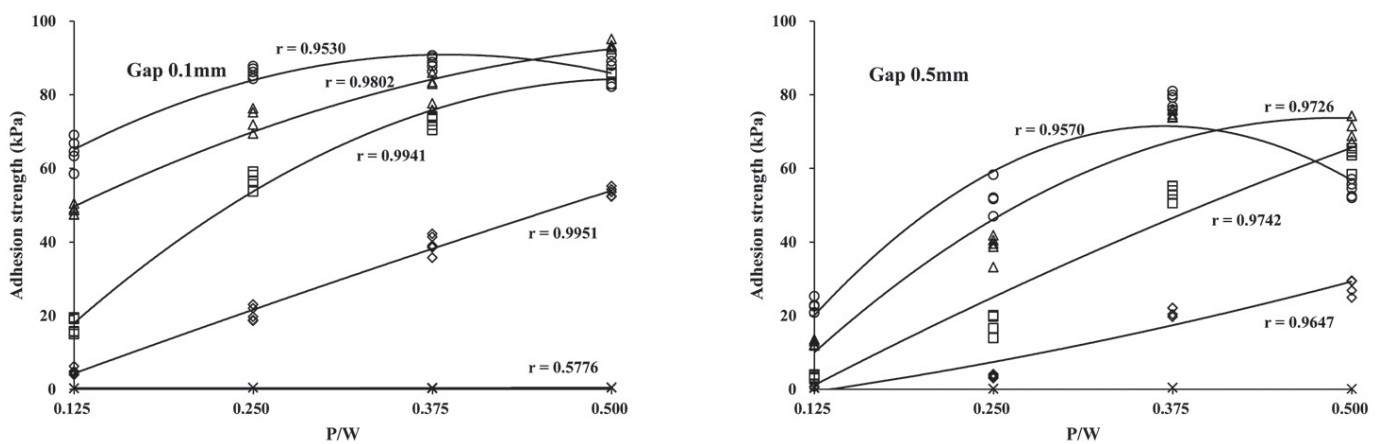

O 100\%CMC-Na / 0\%PVM-MA $\triangle 75 \%$ CMC-Na / $25 \%$ PVM-MA 口 50\%CMC-Na / 50\%PVM-MA $\triangle 25 \%$ CMC-Na / 75\%PVM-MA $\times 0 \% \mathrm{CMC}-\mathrm{Na} / \mathbf{1 0 0} \% \mathrm{PVM}-\mathrm{MA}$

Fig. 4 Relationship between adhesion strength of powder-type DA based on CMC-Na and PVM-MA and P/W ratio for gaps of 0.1 and $0.5 \mathrm{~mm}$.

Table 2 Two-way ANOVA for initial viscosity of powder-type denture adhesives based on CMC-Na and PVM-MA

\begin{tabular}{lrccccc}
\hline \multicolumn{1}{c}{ Source } & df & $\begin{array}{c}\text { Sum of } \\
\text { squares }\end{array}$ & Mean square & F & $\begin{array}{c}\text { Significance } \\
\text { of F }\end{array}$ & $\begin{array}{c}\text { Contribution } \\
\text { ratio } \rho(\%)\end{array}$ \\
\hline Ratio of CMC-Na and PVM-MA & 4 & $6.979 \times 10^{8}$ & $1.745 \times 10^{8}$ & 319.193 & 0.000 & 42.2 \\
P/W ratio & 3 & $6.227 \times 10^{8}$ & $2.076 \times 10^{8}$ & 379.721 & 0.000 & 37.7 \\
$\begin{array}{l}\text { Ratio of CMC-Na and } \\
\text { PVM-MA×P/W ratio }\end{array}$ & 12 & $2.849 \times 10^{8}$ & $2.374 \times 10^{7}$ & 43.432 & 0.000 & 16.9 \\
Error & 80 & $4.373 \times 10^{7}$ & $546,606.01$ & - & - & 3.3 \\
Total & 100 & $2.784 \times 10^{9}$ & - & - & - & - \\
Corrected total & 99 & $1.649 \times 10^{9}$ & - & - & - & - \\
\hline
\end{tabular}

viscosity for the powder-type DA $(p<0.0005$, Table 2$)$. The contribution of the weight ratio of CMC-Na to PVMMA was highest $(\rho=42.2 \%)$, followed by that of the P/W ratio $(\rho=37.7 \%)$, suggesting that the former has more influence on viscosity than the latter. The influence of the $\mathrm{P} / \mathrm{W}$ ratio on initial viscosity was higher than that on adhesion strength. The influences of the weight ratio of CMC-Na to PVM-MA and P/W ratio on viscosity are shown in Figs. 5 and 6, respectively. The viscosity of all DA increased with increasing percentage of CMC-Na and $\mathrm{P} / \mathrm{W}$ ratio. A positive linear relationship was found between viscosity and both percentages of CMC-Na and $\mathrm{P} / \mathrm{W}$ ratio $(\mathrm{r}=0.7686-0.9853, p<0.0005)$, except for $0 \% \mathrm{CMC}-\mathrm{Na} / 100 \% \mathrm{PVM}-\mathrm{MA}$. The viscosity of $100 \% \mathrm{CMC}$ $\mathrm{Na} / 0 \%$ PVM-MA was higher than that of $0 \% \mathrm{CMC}$ $\mathrm{Na} / 100 \%$ PVM-MA for all P/W ratios.

Relationship between adhesion strength and initial viscosity

The relationship between adhesion strength and initial viscosity for the powder-type DA is shown in Fig. 7. The initial viscosity and adhesion strength 


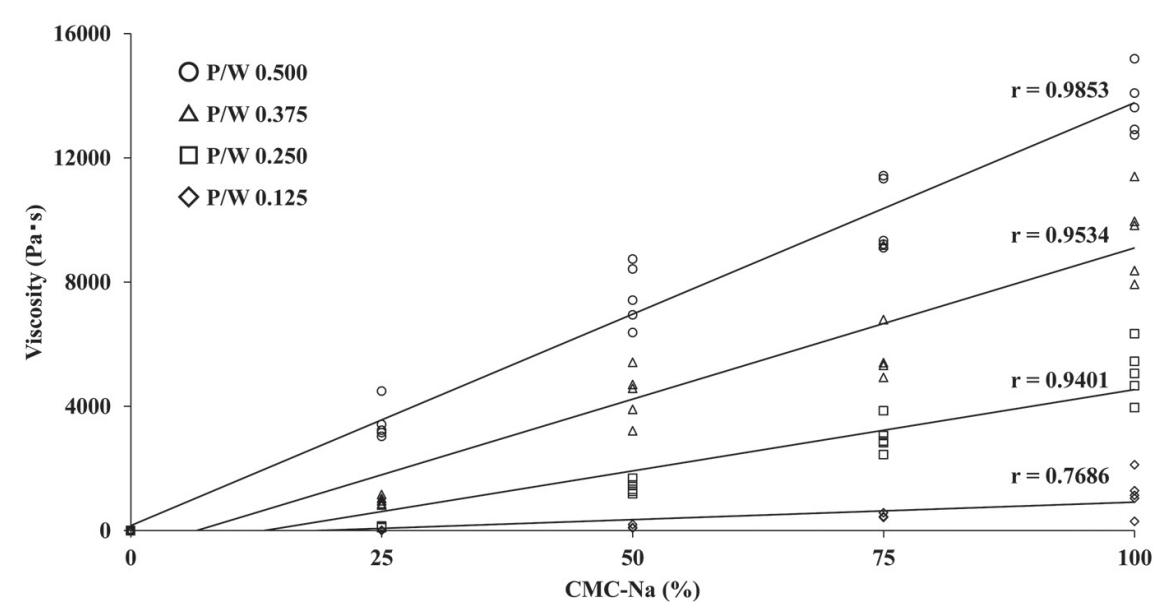

Fig. 5 Relationship between viscosity of powder-type DA based on CMC-Na and PVM-MA and weight ratio of CMC-Na to PVM-MA.

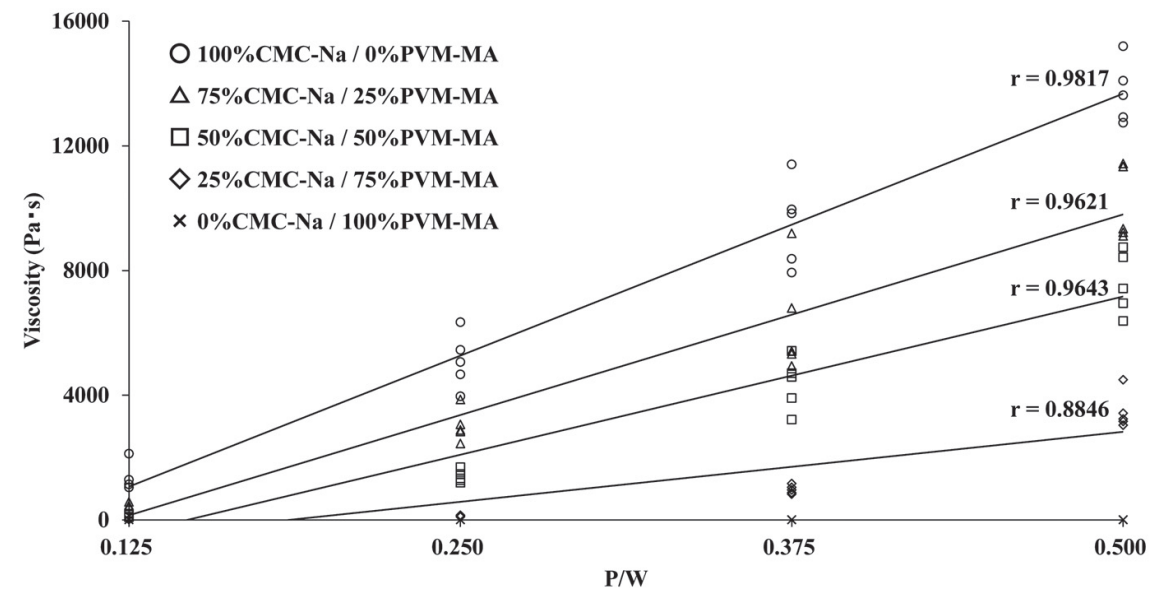

Fig. 6 Relationship between viscosity of powder-type DA based on CMC-Na and PVM-MA and P/W ratio.

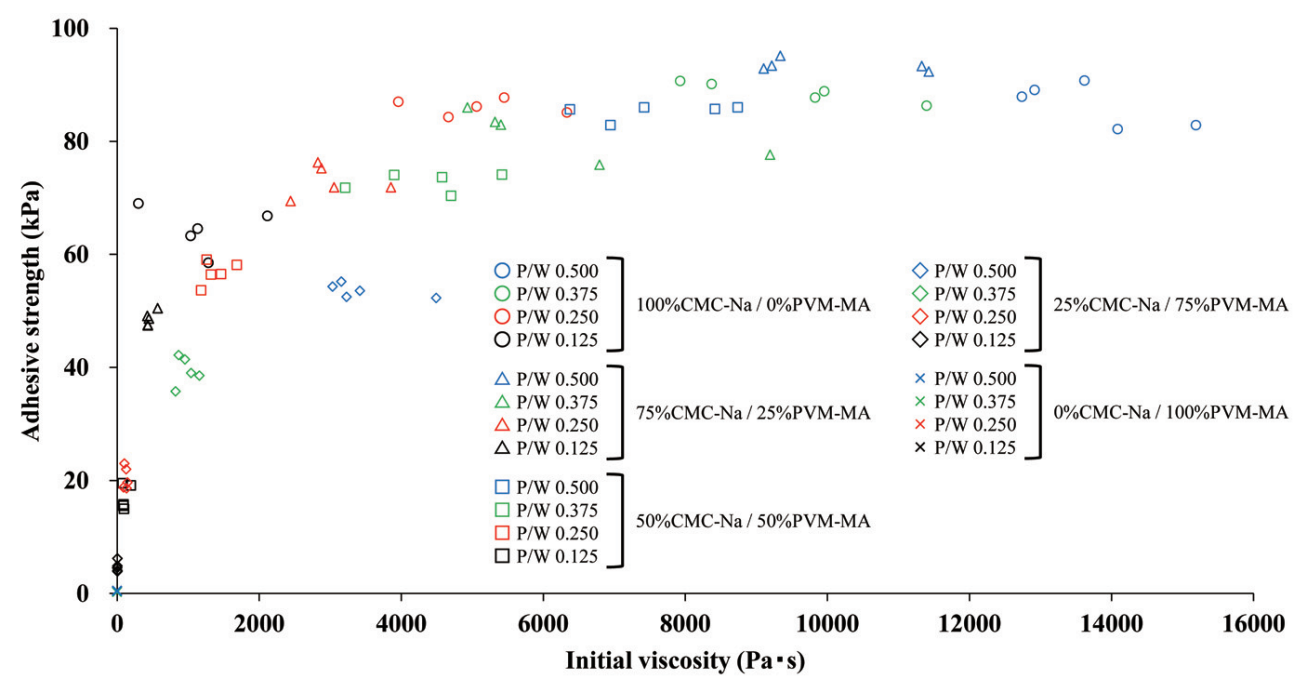

Fig. 7 Relationship between adhesion strength and initial viscosity of powder-type DA based on CMC-Na and PVM-MA. 
for all DA are plotted on the horizontal and vertical axes, respectively. For low initial viscosities, adhesion strength increased with increasing initial viscosity. However, for high viscosities, adhesion strength became almost independent of initial viscosity.

\section{DISCUSSION}

The results show that the weight ratio of $\mathrm{CMC}-\mathrm{Na}$ to PVM-MA and P/W ratio influence the adhesion strength and initial viscosity of powder-type DA. A higher percentage of CMC-Na and a higher $\mathrm{P} / \mathrm{W}$ ratio led to higher viscosity. Furthermore, nearly all DA with a higher percentage of CMC-Na and a higher $\mathrm{P} / \mathrm{W}$ ratio had higher adhesion strength.

For effective use, DA require certain characteristics, such as high strength of adhesion to the prosthesis, suitable viscosity, high biocompatibility, suitable $\mathrm{pH}$ level, high stability, and good washability. It was previously reported that a larger denture intaglio surface, better fit between the denture and the denturebearing mucosa, higher hydrophilicity of the resin, and higher viscosity and larger amount of saliva lead to stronger adhesion to the denture base resin ${ }^{30}$. In the present study, the strength of adhesion to acrylic resin and viscosity, which influences adhesion strength, were evaluated because the clinical efficacy of DA, in terms of masticatory function, occlusal force, and satisfaction of denture wearers, highly depends on these properties. The adhesion strength and viscosity greatly influence denture retention and stability, as well as the fit between the denture intaglio surface and the denture-bearing mucosa. Viscosity affects DA manipulation when DA is applied by the user and spread under the denture intaglio surface.

We measured adhesion strength using a method for which the DA thickness is kept constant prior to tensile measurements, as described in a previous study ${ }^{28}$, but did not apply a constant load. DA thicknesses of 0.1 and $0.5 \mathrm{~mm}$ were used; these values have been observed for well- and ill-fitting dentures, respectively ${ }^{31}$. The $\mathrm{P} / \mathrm{W}$ ratio in the present study ranged from 0.125 to 0.500 . Although no information regarding the $\mathrm{P} / \mathrm{W}$ ratio applied by users is available, a ratio of 0.250 is given in ISO specification $10873^{4}$. Furthermore, our preliminary experiment of sensory evaluation demonstrated that P/W ratios from approximately 0.12 to 0.45 would likely be the appropriate range. Thus, $\mathrm{P} / \mathrm{W}$ ratios of 0.125 to 0.500 were used. We found that adhesion strength decreased with increasing DA layer thickness, indicating that the strength of adhesion to an ill-fitting denture is lower than that to a well-fitting one. Furthermore, our results demonstrated that the DA layer between the denture intaglio surface and the denture-bearing mucosa should be thin to improve retention. A previous study on denture retention showed that the adhesion strength between two disks, $\mathrm{F}$, is given by $\mathrm{F}=\left(2 \pi \mathrm{a}^{2} \cos \theta / \mathrm{h}+3 \eta \pi \mathrm{a}^{4} / 2 \mathrm{~h}^{3} \times \mathrm{dh} /\right.$ $\mathrm{dt}) \times 10^{-3}$, where $\mathrm{a}$ is the radius of a disk; $\theta$ is the receding contact angle, and $\mathrm{h}$ is the thickness of the liquid layer between the two disks ${ }^{30}$. This equation shows that the adhesion strength decreases with increasing DA layer thickness, which is consistent with the results obtained in the present study. It is presumed that a thicker DA layer would lead to cohesive failure relatively compared to adhesive failure. The lateral deformation that occurs during the tensile test in specimens with a thick layer is greater than that in those with a thin layer ${ }^{32}$. The lateral deformation concentrates the force in the area of reduced diameter, which causes the bond of DA to acrylic resin to fail earlier in specimens with a thicker DA layer for a given load. Patients should apply only the minimum amount necessary to produce a thin layer and they must bite the denture sufficiently hard in order to thinly spread the DA.

CMC-Na and PVM-MA were chosen for the present study because they are widely used as fundamental components in powder-type DA. Karaya gum is used in some powder-type DA. However, karaya gum-based DA have a lower $\mathrm{pH}$ value (approximately 4.5 to 4.7 ) than that of DA with CMC-Na and PVM-MA ${ }^{333}$. The $\mathrm{pH}$ value of karaya gum-based DA is lower than the critical $\mathrm{pH}$ of enamel; the use of such DA might thus lead to decalcification. Karaya gum is therefore unsuitable for DA. CMC-Na and PVM-MA contain several types of polar group (e.g., ionic, hydroxyl, amino, amide, and ether groups) that have strong interaction with water molecules. CMC-Na is one of the most commonly used water-soluble polymers and is very safe ${ }^{34,35)}$. PVM-MA is also commonly used in commercial products including DA.

Although the demand for DA is increasing with increasing intractable cases of dentures, there is a lack of ideal powder-type DA that have high strength of adhesion to the denture base and stable viscosity regardless of added water. Our results show that a higher percentage of CMC-Na and a higher P/W ratio tended to result in higher adhesion to acrylic resin, and that the effect of the weight ratio of CMC-Na to PVM-MA was much greater than that of the $\mathrm{P} / \mathrm{W}$ ratio, as indicated by the contribution ratios obtained from ANOVA. Furthermore, we found that a higher percentage of $\mathrm{CMC}-\mathrm{Na}$ and a higher $\mathrm{P} / \mathrm{W}$ ratio led to greater viscosity. The effect of the weight ratio of CMC-Na to PVM-MA was larger than that of the $\mathrm{P} / \mathrm{W}$ ratio. The DA consisting of only PVM-MA had lower adhesion strength and viscosity. DA containing a higher percentage of CMC-Na had higher initial viscosity because the viscosity of the mixture of CMC-Na and water is greater than that of PVM-MA and water. Although greater force is necessary to separate materials with higher viscosity from acrylic resin, as shown in a previous study ${ }^{30}$, it is necessary to consider the time-dependence of viscosity in clinical settings.

Based on these findings, DA containing a higher percentage of CMC-Na and higher powder content should lead to higher denture retention and stability. However, even though DA with high viscosity tended to have higher adhesion strength, the adhesion strength of the DA with the highest viscosity $(100 \% \mathrm{CMC}-\mathrm{Na} / 0 \% \mathrm{PVM}-$ MA, P/W ratio: 0.500) (13,712 $\pm 988 \mathrm{~Pa} \cdot \mathrm{s})$ was lower than those of DA with lower viscosity $(100 \% \mathrm{CMC}-\mathrm{Na} / 0 \% \mathrm{PVM}$ - 
MA, P/W ratio: $0.375,75 \% \mathrm{CMC}-\mathrm{Na} / 25 \% \mathrm{PVM}-\mathrm{MA}, \mathrm{P} / \mathrm{W}$ ratio: 0.500 , and $75 \% \mathrm{CMC}-\mathrm{Na} / 25 \% \mathrm{PVM}-\mathrm{MA}, \mathrm{P} / \mathrm{W}$ ratio: 0.375). It was also found that an excessively high DA viscosity was associated with a reduction in the strength of adhesion to acrylic resin. These results indicate that DA with an initial viscosity of approximately 9,500 to $10,000 \mathrm{~Pa}$ s at $1.0 \mathrm{~s}^{-1}$ will have the highest adhesion strength. This information is useful for suggesting the amount of powder to use and how to apply the powder and water to obtain adequate viscosity. The obtained relationship between the properties and weight ratio of CMC-Na to PVM-MA can be used to develop DA with clinically effective adhesion strength and viscosity.

CMC-Na and PVM-MA are included in many DA. Although CMC-Na plays a major role in the increase of viscosity and adhesion strength in the initial stage, its efficacy can decrease over time due to dissolution. PVM-MA, which is less soluble in water ${ }^{29)}$, may help to maintain the initial properties of the DA for an extended period. Further study of the relationship between composition and durability is necessary.

From the viewpoint of manipulation by denture wearers, DA with a lower initial viscosity are preferred, because they can be spread uniformly onto the intaglio surface of the dentures when applied, avoiding malocclusion. DA with an excessively high viscosity, such as liner type DA, can increase the occlusal vertical dimension and cause unbalanced occlusion of dentures, leading to resorption of the residual ridge ${ }^{22}$. However, from the viewpoint of the strength of adhesion to the denture, DA with higher viscosity are preferable, because high viscosity leads to higher adhesion strength. Our previous study demonstrated that commercially available DA have an adhesion strength of approximately 4 to $14 \mathrm{kPa}$ when measured using the method used in the present study at a DA thickness of $0.5 \mathrm{~mm}^{28}$. The adhesion strength values of the DA prepared in the present study covered the range of 4 to $14 \mathrm{kPa}$. Although adhesion strength requirements are specified in ISO specification $10873^{4}$ ), a suitable viscosity for manipulation by patients has not yet been determined. In addition, the behavior of DA in the mouth has not been determined. An investigation using sensory analysis of patients and dentists and an investigation on the influence of temperature on some properties are necessary to determine clinically suitable rheological properties for DA. Furthermore, viscosity and the strength of adhesion to acrylic resin in clinical settings are influenced by time when deformation is applied. An analysis of the relationship between the clinical behavior of DA and time is necessary for a rigorous evaluation.

One of the advantages of powder-type DA is that patients can adjust viscosity via the addition of water to the powder; however, this is rather difficult to effectively perform. An ideal powder-type DA would have high adhesion strength when used in small amounts and have properties that are not influenced by the amount of added water. The present findings should contribute to the development and improvement of both powder- and cream-type DA.

\section{CONCLUSIONS}

Within the limitations of this study, the following conclusions can be made:

1. The strength of adhesion to acrylic resin for powder-type DA based on CMC-Na and PVM-MA tended to increase with increasing $\mathrm{P} / \mathrm{W}$ ratio and especially the percentage of CMC-Na.

2. The initial viscosity of the powder-type DA increased with increasing $\mathrm{P} / \mathrm{W}$ ratio and percentage of CMC-Na.

3. Although powder-type DA with higher viscosity tended to show greater adhesion strength, adhesion strength decreased when viscosity exceeded a certain level.

4. The adhesion strength and initial viscosity of DA can be controlled and improved by varying the $\mathrm{P} / \mathrm{W}$ ratio and especially the weight ratio of CMC$\mathrm{Na}$ to PVM-MA over a wide range.

\section{ACKNOWLEDGMENTS}

A summary of the results of this study was presented at the 96th General Session \& Exhibition of the IADR in London, July 2018. This work was supported by JSPS KAKENHI under Grant Number 16K15806.

\section{REFERENCES}

1) Ivanhoe JR, Cibirka RM, Parr GR. Treating the modern complete denture patient: a review of the literature. J Prosthet Dent 2002; 88: 631-635.

2) Slaughter A, Katz RV, Grasso JE. Professional attitudes toward denture adhesives: A Delphi Technique survey of academic prosthodontists. J Prosthet Dent 1999; 82: 80-89.

3) The Japanese Society for Dental Materials and Devices. A glossary for dental materials and devices. Tokyo: Ishiyaku Publishers Inc; 2005. p.20.

4) International Organization for Standardization (2010) ISO 10873. Dentistry-Denture adhesives.

5) Kelsey CC, Lang BR, Wang RF. Examining patients' responses about the effectiveness of five denture adhesive pastes. J Am Dent Assoc 1997; 128: 1532-1538.

6) Uysal H, Altay OT, Alparslan N, Bilge A. Comparison of four different denture cushion adhesives: a subjective study. J Oral Rehabil 1998; 25: 209-213.

7) Ozcan M, Kulak Y, Arikan A, Silahtar E. The attitude of complete denture wearers towards denture adhesives in Istanbul. J Oral Rehabil 2004; 31: 131-134.

8) Nicolas E, Veyrune JL, Lassauzay C. A six-month assessment of oral health-related quality of life of complete denture wearers using denture adhesive: a pilot study. J Prosthodont 2010; 19: 443-448.

9) Polyzois GL, de Baat C. Attitudes and usage of denture adhesives by complete denture wearers: a survey in Greece and the Netherlands. Gerodontology 2012; 29: 807-814.

10) Papadiochou S, Emmanouil I, Papadiochos I. Denture adhesives: a systematic review. J Prosthet Dent 2015; 113: 391-397.

11) Grasso JE, Rendell J, Gay T. Effect of denture adhesive on the retention and stability of maxillary dentures. J Prosthet Dent 1994; 72: 399-405.

12) Pradies G, Sanz I, Evans O, Martnez F, Sanz M. Clinical study comparing the efficacy of two denture adhesives in complete denture patients. Int J Prosthodont 2009; 22: 361- 
367.

13) Munoz CA, Gendreau L, Shanga G, Magnuszewski T, Fernandez P, Durocher J. A clinical study to evaluate denture adhesive use in well-fitting dentures. J Prosthodont 2012; 21: 123-129.

14) Rendell JK, Gay T, Grasso JE, Baker RA, Winston JL. The effect of denture adhesive on mandibular movement during chewing. J Am Dent Assoc 2000; 131: 981-986.

15) Gonçalves TM, Viu FC, Gonçalves LM, Garcia RC. Denture adhesives improve mastication in denture wearers. Int $\mathrm{J}$ Prosthodont 2014; 27: 140-146.

16) de Oliveira Jr NM, Rodriguez LS, Mendoza Marin DO, Paleari AG, Pero AC, Compagnoni MA. Masticatory performance of complete denture wearers after using two adhesives: a crossover randomized clinical trial. J Prosthet Dent 2014; 112: 1182-1187.

17) Sipahi C, Beyzadeoglu M, Demirtas S, Ozen J. Effect of different mucosal and acrylic resin surface treatments in a denture retention model for patients with radiotherapyinduced xerostomia. Int J Prosthodont 2007; 20: 405-408.

18) Bogucki ZA, Napadlek P, Dabrowa T. A clinical evaluation denture adhesives used by patients with xerostomia. Medicine (Baltimore) 2015; 94: 545.

19) Bartlett DW, Maggio B, Targett D, Fenlon MR, Thomas J Thomas. A preliminary investigation into the use of denture adhesives combined with dietary advice to improve diets in complete denture wearers. J Dent 2013; 41: 143-147.

20) Woelfel JB, Kreider JA. Home reliner ruins dentures and causes shrinkage. J Prosthet Dent 1968; 20: 319-325.

21) Felton D, Cooper L, Duqum I, Minsley G, Guckes A, Haug S, et al. Evidence-based guidelines for the care and maintenance of complete dentures: a publication of the American College of Prosthodontists. J Am Dent Assoc 2011; 142 Suppl 1: 1S$20 \mathrm{~S}$.

22) Murata H, Hong G, Yamakado C, Kurogi T, Kano H, Hamada T. Dynamic viscoelastic properties, water absorption, and solubility of home reliners. Dent Mater J 2010; 29: 554-561.

23) Ellinger CW. Extensive damage to the lower ridge caused by use of home reliner by a patient. Fortn Rev Chic Dent Soc 1965; 49: 13-15.

24) Ellis B, Al-Nakash S, Lamb DJ. The composition and rheology of denture adhesives. J Dent 1980; 8: 109-118.

25) Takahashi H. Type and characteristics of denture adhesives. J Jpn Prosthodont Soc 2003; 47: 474-483.

26) Love WB, Biswas S. Denture adhesives: $\mathrm{pH}$ and buffering capacity. J Prosthet Dent 1991; 66: 356-360.

27) Panagiotouni E, Pissiotis A, Kapari D, Kaloyannides A. Retentive ability of various denture adhesive materials: an in vitro study. J Prosthet Dent 1995; 73: 578-585.

28) Kano H, Kurogi T, Shimizu T, Nishimura M, Murata H. Viscosity and adhesion strength of cream-type denture adhesives and mouth moisturizers. Dent Mater J 2012; 31: 960-968.

29) Han JM, Hong G, Hayashida K, Maeda T, Murata H, Sasaki $\mathrm{K}$. Influence of composition on the adhesive strength and initial viscosity of denture adhesives. Dent Mater J 2014; 33: 98-103.

30) Iida Y. Physical factors in denture retention. Bull Tokyo Med Dent Univ 1975; 22: 113-125.

31) Miyata T. A study on denture-base fitness of extention-base partial dentures. J Jpn Prosthodont Soc 1976; 20: 694-710.

32) al-Athel MS, Jagger RG. Effect of test method on the bond strength of a silicone resilient denture lining material. J Prosthet Dent 1996; 76: 535-540.

33) Lamb DJ, Craig GT. Demineralization of human dental enamel by karaya gum solutions. Caries Res 1982; 16: 118122.

34) Mamdouh T. Ghannam, Nabil Esmail. Rheological properties of carboxymethyl cellulose. J Appl Polym Sci 1997; 64: 289301.

35) Jacqueline IK. Concise encyclopedia of polymer science and engineering. New York: John Wiley \& Sons, Inc.; 1990. 